the population who have a more acute perception of any deterioration in memory than the general population or they may have had a subclinical depressive illness. Our tests may not be sensitive enough to detect a small change in function that can be noticed by patients with a high degree of self awareness and insight. This subjective feeling of "things not being quite right" has been reported previously and may last for up to 30 days after general anaesthesia in young volunteers. ${ }^{334}$ Conversely, there is evidence that patients may report themselves as fully recovered and back to normal and still have a measurable decrease in function. ${ }^{3536}$

In conclusion, using objective and subjective measures of both cognitive and functional competence, we found that modern anaesthesia, either general or regional, seemed to have no significant long term effects on mental function in elderly patients.

We thank Astra Pharmaceuticals for financial support, $\mathrm{Ms}$ $H$ Altman for conducting the interviews with patients and the psychometric assessments, and Mrs R Douglas and Mrs H P Hughes for administrative help.

1 Bulstrode C. Keeping up with orthopaedic epidemics. Br Med f 1987;295:514. 2 Bedford PD. Adverse cerebral effects of anaesthesia on people. Lance 1955;ii:259-63.

1955;ii:259-63.
Simpson BR, Williams M, Scott JF, Crampton-Smith A. The effects of Simpson BR, Williams M, Scott JF, Crampton-Smith A. The effects
anaesthesia and elective surgery on old people. Lancet 1961;ii:887-93.

Wollman SB, Orkin LR. Postoperative human reaction time and hypocarbia during anaesthesia. Br f Anaesth 1968;40:920-6.

5 Murrin KR, Nagarajan TM. Hyper-ventilation and psychometric testing. Anaesthesia 1974;29:50-8.

6 Prior FN, Chander P. Air as a vapourizing gas. Cognitive functions in elderly patients undergoing anaesthesia. Br $\mathcal{F}$ Anuesth 1982;54:1207-11.

7 Rollason WN, Robertson GS, Cordiner CM, Hall DJ. A comparison of mental function in relation to hypotensive and normotensive anaesthesia in the elderly. Br f Anaesth 1971;43:561-5.

8 Thompson GE, Miller RD, Stevens WC, Murray WR. Hypotensive anesthesia for total hip arthroplasty. Anesthesiology 1978;48:91-6.

9 Hodkinson HM. Mental impairment in the elderly. $f R$ Coll Physicians Lond 1973;7:305-17.

10 Blundell E. A psychological study of the effects of surgery on eighty-six elderly patients. British fournal of Social and Clinical Psychology 1967;6:297-303.

1 Millar HR. Psvchiatric morbidity in elderly surgical patients. Br f Psychiatry $1981 ; 138: 17-20$

12 Berggren D, Gustafson Y, Eriksson B, et al. Postoperative confusion after anesthesia in elderly patients with femoral neck fractures. Anesth Analg 1987;66:497-504
3 Hole A, Teriesen T, Breivik $\mathrm{H}$. Epidural versus general anaesthesia for total hip arthroplasty in elderly patients. Acta Anaesthiol Scand 1980;24:279-87. 4 Riis J, Lomholt B, Haxholdt $\mathrm{O}$, et al. Immediate and long-term mental recovery from general versus epidural anaesthesia in elderly patients. Acta Anaesthiol Scand 1983;27:44-9.

15 Chung F, Meier R, Lautenschlager E, et al. General or spinal anesthesia; which is better in the elderly? Anesthesiology 1987;67:422-7.

16 Ghoneim MM, Hinrichs JV, O'Hara MW, et al. Comparison of psychologic and cognitive function after general or regional anesthesia. Anesthesiology 1988;69:507-15.

17 Zelen $M$. A new design for randomised clinical trials. $N$ Engl f Med 1979;300:1242-5.

18 Zelen M. Alternatives to classic randomised trials. Surg Clin North Am 1981;61:1425-32

19 Nelson HE. National adult reading test (NART) test manual. Windsor: National Foundation for Educational Research-Nelson, 1982.

20 Hindmarch I, Parrott AC. Repeated dose comparison of nomifensine, unipranine and placebo on subjective assessments of sleep and objective measures of psychomotor performance. Br f Clin Pharmacol 1976;4: 1675-735.

21 Hindmarch I. 1-4 Benzodiazepine, temazepam (K3917). Its effect on some psychological parameters of sleep amd behaviour. Arzneimittelforschung 1975;25:1836-9.

22 Kendrick DC. The Kendrick cognitive tests for the elderly. Windsor: National Foundation for Educational Research-Nelson, 1986.

23 Sarno JE, Sarno MT, Levita E. Functional life scale. Arch Phys Med Rehabil $1973 ; 54: 214-20$

24 McNair DM, Kahn RJ. Self-assessment of cognitive deficits. In: Crook T, Ferris S, Bartus R, eds. Assessment in geriatric psychopharmacolgy. Connecticut: Mark Powly, 1983:137-44.

25 Newcombe RG. Explanatory and pragmatic estimates of the treatment effect when deviations from allocated treatment occur. Stat Med 1988;7:1179-86.

26 Davenport HT. Anaesthesia in the elderlv. London: Heinemann Medical, 1986:ix.

27 Anonymous. Postoperative fatigue [Editorial]. Lancet 1979;i:84-5.

28 Edwards H, Rose EA, Schorow M, King TC. Postoperative deterioration in psards H, Rose EA, Schorow M, King TC. Pos
psychomotor function. FAMA 1981;245:1342-3.

29 Williams EI, Fitton F. Factors affecting early unplanned readmission of elderly patients to hospital. Br Med $\mathcal{F} 1988 ; 297: 784-7$.

30 Bigler D, Adelhoj B, Petring OU, Busch P, Kalhke P. Mental function and morbidity after acute hip surgery during spinal and general anaesthesia. Anaesthesia 1985;40:672-6.

31 Karhunen U, Jonn $\mathrm{G}$. A comparison of memory function following local and general anaesthesia for extraction of senile cataract. Acta Anaesthiol Scand 1982;26:291-6.

32 Thorburn J, Louden JR, Vallance R. Spinal and general anaesthesia in total hip replacement: frequency of deep vein thrombosis. Br $\mathcal{F}$ Anaesth 1980;52: $1117-20$.

33 James FM. The effects of cyclopropane anesthesia without surgical operation in mental functions of normal man. Anesthesiology 1969;30:264-72.

34 Davison LA, Steinhelber JC, Eger EI, Stevens WC. Psychological effects of halothane and isoflurane anesthesia. Anesthesiology 1975;43:313-24.

35 Egbert LD, Oech SR, Eckenhoff JE. Comparison of the recovery from methohexital and thiopental anesthesia in man. Surg Gynecol Obstet 1959;109:427-30.

36 Herbert $M$, Healy TEJ, Bourke JB, Fletcher IR, Rose JM. Profile of recovery after general anaesthesia. Br Med f 1983;286:1539-42.

(Accepted 3 April 1990)
Departments of Clinical Pharmacology and Medical Statistics, North

Staffordshire Health

Authority, Stoke on

Trent ST 4 6QG

Sandra Kuhn, SRN, research sister

Karen Cooke, SEN, research nurse

Michael Collins, PHD, district medical statistician

J Mary Jones, PHD, district medical statistician

John C Mucklow, FRCP, consultant clinical

pharmacologist

Correspondence to:

Mrs Kuhn.

\title{
Perceptions of pain relief after surgery
}

\author{
Sandra Kuhn, Karen Cooke, Michael Collins, J Mary Jones, John C Mucklow
}

\section{Abstract}

Objective-To assess patients' satisfaction with postoperative pain relief.

Design-A descriptive and questionnaire study of patients' experience.

Setting-Two surgical and two gynaecological wards.

Patients -50 Patients admitted to hospital for cholecystectomy and 51 admitted for hysterectomy.

Main outcome measures-Visual analogue scales with no divisions were completed by the patients immediately after each dose of postoperative analgesia was administered throughout their stay in hospital. A questionnaire completed on the fifth postoperative day recorded patients' recollections of their experience. Opinions were also sought from medical and nursing staff.

Results-During the first $\mathbf{2 4}$ hours after surgery recorded pain levels were $60 \%$ of the maximum and were not influenced by age, sex, or the type of operation performed. The median interval between the return of pain and a further injection of analgesic was 2 hours (interquartile range 1 to 3.5 hours). Expectations of pain relief were low, and for $70 \%$ of the patients the pain was at least as bad as they had expected. Only half of the medical and nursing staff questioned thought that postoperative analgesia should relieve pain completely; drugs were prescribed and administered with too little attention to the patient's response and too much concern about adverse effects and opioid dependence.

Conclusions - The results suggest that the standard of postoperative pain relief is poor because of inadequate education of patients in what to expect (and demand), and of medical and nursing staff in how to prescribe and administer analgesia with reference to individual drug response.

\section{Introduction}

Ineffective relief of postoperative pain is an unacceptable but common sequel to surgery. Cohen found that $37 \%$ of patients who had elective abdominal operations were in severe pain afterwards, ${ }^{\prime}$ and $42 \%$ of patients questioned by Cronin et al after similar procedures described the pain they experienced as "very unpleasant indeed.".

The reasons for inadequate pain relief include 
shortcomings in both the prescription and the administration of drugs, and anxiety about addiction is still prevalent. ${ }^{3}$ One study showed that when nurses were allowed to choose from a range of drug doses the lowest dose was chosen repeatedly, regardless of the patient's response'; complete pain relief was considered an objective that could not safely be achieved.

Despite the many studies of postoperative pain and its effects information is scanty about the severity, frequency, and duration of pain that patients experience after common operations. We conducted a study to assess the quality of postoperative pain relief with particular reference to patients' perceptions.

\section{Patients and methods}

All patients admitted for elective abdominal hysterectomy or cholecystectomy to four surgical wards at the City General Hospital, Stoke on Trent, during eight months were invited to enter the study; oral consent was obtained from all patients. Shortly after admission each patient was asked about any previous experience of postoperative pain. Age, weight, duration of illness, and current drug treatment were also recorded.

A visual analogue scale with no divisions was used by patients to define grades of pain. ${ }^{+}$The end points of the $10 \mathrm{~cm}$ line were "no pain at all" and "pain as bad as it could be." Before surgery the patients were shown how to use the scale and their understanding of its use was confirmed. Patients were asked to assess their pain immediately after each dose of analgesia was given throughout their hospital stay. On the fifth postoperative day a questionnaire was completed for each patient, recording his or her opinions about the operation and related experiences. After discharge from hospital a record was made of all anaesthetic and other drugs each patient had received after his or her operation.

After the data on all patients had been collected a questionnaire on prescribing habits and attitudes to postoperative pain relief was sent to 32 medical staff and 93 nursing staff on the wards included in the study.

\section{STATISTICAL METHODS}

The average number of anaesthetic drugs and doses of analgesia for patients who had a cholecystectomy and those who had a hysterectomy were compared by $t$ tests. The proportion of total analgesic doses that were opioids in the two groups were compared by the $\chi^{2}$ test. The scores for pain were analysed according to operation and sex for each postoperative day with $t$ tests. Correlation coefficients were calculated to evaluate the effect of age on scores for pain. As multiple significance tests increase the probability of obtaining false significant effects a significance level of 0.01 was used.

\section{Results}

Of 137 patients approached, 133 agreed to take part; the four who refused said that they were too anxious to participate in the study. One patient was withdrawn as she was unable to understand how to use the visual analogue scale, one patient discharged himself before the operation, and six had an operation other than that for which they were admitted. A further 15 patients in the hysterectomy group and nine in the cholecystectomy group either completed none of the visual analogue scales or completed too few for their results to be included.

Of the remaining 101 patients, 51 had a hysterectomy and 50 a cholecystectomy. Table I shows their age, sex weight, length of stay in hospital, and relevant medical and surgical history. Seventy five patients had had
TABLE I-Demographic and other data on patients according to operation received

\begin{tabular}{lcc}
\hline & $\begin{array}{c}\text { Hysterectomy } \\
(\mathrm{n}=51)\end{array}$ & $\begin{array}{c}\text { Cholecystectomy } \\
(\mathrm{n}=50)\end{array}$ \\
\hline $\begin{array}{l}\text { Mean (SD) age (years) } \\
\text { Sex (F/M) }\end{array}$ & $\begin{array}{c}44 \cdot 4(7 \cdot 7) \\
51\end{array}$ & $\begin{array}{c}53 \cdot 2(14 \cdot 2) \\
38 / 12\end{array}$ \\
$\begin{array}{l}\text { Mean (SD) weight (kg) } \\
\text { No of patients taking analgesics on } \\
\text { admission }\end{array}$ & $66 \cdot 0(10 \cdot 2)$ & $68 \cdot 3(12 \cdot 8)$ \\
$\begin{array}{l}\text { Median (quartiles) duration of illness } \\
\text { (months) }\end{array}$ & 6 & 20 \\
$\begin{array}{l}\text { No of patients who had had surgery } \\
\text { previously }\end{array}$ & $24(12,48)$ & $9(4,24)$ \\
$\begin{array}{l}\text { Median (quartiles) duration of hospital } \\
\text { stay (days) }\end{array}$ & 71 & 34 \\
\hline
\end{tabular}

surgery in the past, but 42 of them could not recall how much postoperative pain they had experienced.

The number of anaesthetic drugs used for each patient did not differ significantly $(\mathrm{p}=0.60)$ between the cholecystectomy group (mean $8 \cdot 0$ ) and the hysterectomy group (mean 7.9), and there were too many different types of anaesthetics to make a comparison of their effects on postoperative pain.

The use of opioids during surgery did not have a significant effect on the first score for pain (cholecystectomy group $p=0 \cdot 72$, hysterectomy group $p=0 \cdot 38$ ).

All patients who had a hysterectomy and all but two who had a cholecystectomy were given papaveretum $10-20 \mathrm{mg}$ as their first postoperative analgesic. The patients in the hysterectomy group received a total of 873 doses of analgesia (mean for each patient 17, range $4-25), 209(24 \%)$ of which were opioids. In the cholecystectomy group a total of 564 doses (mean 10 , range 2-26) were given, $204(37 \%)$ of them opioids. The two groups differed significantly $(p<0.001)$ with respect to average doses of analgesia and the percentage of doses that were opioids.

Only $67 \%(944 / 1419)$ of the visual analogue scales were completed overall (hysterectomy 69\% (605), cholecystectomy $62 \%(339)$ ). On the first postoperative day $62 \%(129 / 207)$ were completed, on days 2 and 3 $83 \%(475 / 569)$ were completed, and then a gradual decrease occurred until on day 6 only $42 \%(57 / 135)$ were completed. Incomplete records occurred either because patients were too drowsy to complete the scale immediately after surgery or because nurses were too busy to ensure that the scales were completed. Analysis of the scales was complicated by variation among patients in the number of doses received, the intervals between doses, and the number of scales completed. The data were therefore analysed daily to derive an average for each day's scores.

Table II shows that pain was moderately severe on the first day after surgery but that there was a gradual reduction of pain during the ensuing days. There was no relation within each age group between pain experienced and either age or sex. Because of the similarity in results between groups they were combined in further analyses.

TABLE II -Mean percentage score for pain recorded on visual analogue scale during first six days after surgery

\begin{tabular}{cccc}
\hline Day & $\begin{array}{c}\text { Hysterectomy } \\
\text { group }\end{array}$ & $\begin{array}{c}\text { Cholecystectomy } \\
\text { group }\end{array}$ & p Value \\
\hline 1 & 60.5 & 62.0 & 0.73 \\
2 & 50.0 & 51.6 & 0.68 \\
3 & 41.9 & 44.3 & 0.58 \\
4 & 31.8 & 37.4 & 0.21 \\
5 & 31.6 & 35.1 & 0.51 \\
6 & 27.8 & 25.9 & 0.69 \\
\hline
\end{tabular}

The interval between return of pain and the next dose of analgesia varied widely among patients (median 2 hours, interquartile range 1 to 3.5 hours); some had no pain at all whereas one patient remained in pain for 17 hours. 
PATIENT QUESTIONNAIRE

When asked "How painful would you say this operation was overall?" 40 of the 101 patients replied very painful and 47 moderately painful, with only 13 having had little or no pain (table III).

Patients were also asked to relate the severity of pain to their expectations; 43 thought that it had been about what they expected, 27 that it had been more severe, and 31 that it had been less severe. All patients were asked how effective they thought pain relief should be (table IV): 36 thought that it should relieve pain completely, 58 thought that it should relieve pain so that they could move comfortably in bed, and five thought that it should just take the edge off the pain.

When asked if they knew that pain relievers had been prescribed for them and that they had only to ask for them if needed 79 patients said yes and 22 said no. Patients were also asked who had informed them before their operation about the pain that they might experience. Only 58 patients said that they had been given any information. Table $\mathrm{V}$ shows who had given this information. Eighty eight patients thought that giving out an information sheet about possible postoperative pain before surgery would be helpful.

To determine whether patients who felt nauseated after their operation received more antiemetics than those who did not the number of antiemetics given was compared with the number prescribed. Fifty nine patients felt nauseated and received $150(26 \%)$ of a possible 576 doses prescribed, whereas 40 patients who did not feel nauseated received $78(23 \%)$ of a possible 343 doses prescribed, a similar percentage in each group. Ninety four patients rejected the suggestion that the injection of the analgesic itself had hurt.

\section{STAFF QUESTIONNAIRE}

A total of 19 doctors (59\%) and 56 nurses $(60 \%)$ returned the staff questionnaire. The surgical staff comprised 11 consultant anaesthetists, two senior surgical registrars, one registrar, four senior house officers, and one house officer. The nursing staff comprised nine sisters, 12 staff nurses, 21 enrolled nurses, and 14 nurses in training. Table II shows the responses to the main questions. Of the 11 staff who

TABLE III - Patients' response when asked how painful they had found operation overall

\begin{tabular}{lcc}
\hline & $\begin{array}{c}\text { Hysterectomy } \\
\text { group }(\mathbf{n}=51)\end{array}$ & $\begin{array}{c}\text { Cholecystectomy } \\
\text { group }(\mathbf{n}=50)\end{array}$ \\
\hline $\begin{array}{l}\text { Very painful } \\
\text { Moderately painful }\end{array}$ & 21 & 19 \\
Little pain & 27 & 20 \\
Painless & 1 & 10 \\
& 1 & 1 \\
\hline
\end{tabular}

TABLE IV-Patients' and medical staff's perceptions of how effective pain relief should be. Values given as percentage (number) of respondents

\begin{tabular}{lccc}
\hline & $\begin{array}{c}\text { Patients } \\
(\mathrm{n}=101)\end{array}$ & $\begin{array}{c}\text { Nurses } \\
(\mathrm{n}=56)\end{array}$ & $\begin{array}{c}\text { Doctors } \\
(\mathrm{n}=19)\end{array}$ \\
\hline Complete relief & $36(36)$ & $50(28)$ & $53(10)$ \\
Comfortable pain & $\begin{array}{r}58(59) \\
\text { Take edge off pain }\end{array}$ & $\begin{array}{r}48(27) \\
2(5)\end{array}$ & $47(9)$ \\
\hline
\end{tabular}

TABLE V-Respondents' opinions about who gives information to patients about possible postoperative pain. Values given as percentage number) of respondents

\begin{tabular}{llll}
\hline & $\begin{array}{l}\text { Patients } \\
(\mathrm{n}=101)\end{array}$ & $\begin{array}{l}\text { Nurses } \\
(\mathrm{n}=56)\end{array}$ & $\begin{array}{l}\text { Doctors } \\
(\mathrm{n}=19)\end{array}$ \\
\hline Doctor & $21(21)$ & $38(21)$ & $32(6)$ \\
Anaesthetist & $11(11)$ & $43(24)$ & $68(13)$ \\
Sister & $17(17)$ & $75(42)$ & $32(6)$ \\
Nurse & $11(11)$ & $93(52)$ & $32(6)$ \\
Family & $28(28)$ & $12(7)$ & $11(2)$ \\
\hline
\end{tabular}

TABLE VI-Responses of nurses and doctors to staff questionnaire. Values given as percentage (number) who agreed

\begin{tabular}{lcc}
\hline Statement & $\begin{array}{l}\text { Nurses } \\
(\mathbf{n}=56)\end{array}$ & $\begin{array}{c}\text { Doctors } \\
(\mathbf{n}=19)\end{array}$ \\
\hline $\begin{array}{l}\text { For most patients the pain relief we provide is } \\
\text { adequate }\end{array}$ & $79(44)$ & $21(4)$ \\
$\begin{array}{l}\text { Postoperative pain may be preferred to the pain } \\
\text { from an injection }\end{array}$ & $41(23)$ & $16(3)$ \\
$\begin{array}{l}\text { Postoperative analgesia should: } \\
\quad \text { Relieve pain completely }\end{array}$ & $50(28)$ & $53(10)$ \\
$\quad$ Merely allow movement in bed & $48(27)$ & $47(9)$ \\
$\quad$ Be given only when the patient is in pain & $66(37)$ & $58(11)$ \\
$\quad \begin{array}{l}\text { Take account of interpatient variation } \\
\text { Opioid analgesics: }\end{array}$ & $95(53)$ & $89(17)$ \\
$\quad$ May cause addiction & $20(11)$ & $5(1)$ \\
$\quad$ Should usually be given with an antiemetic & $95(53)$ & $89(17)$ \\
\hline
\end{tabular}

thought that opioid analgesics given postoperatively could cause addiction, five agreed that this might influence their selection of the dose and dose interval.

\section{Discussion}

The selection of just two operations minimised the variation in the type of wound and in the duration of the operation and the stay in hospital, which might have complicated the analysis in a more heterogeneous sample. Furthermore, there were few differences in the experience related by patients in the two operative groups.

Although the overall number of opioid analgesics given to the patients in each group was similar, the total number of all analgesic doses differed considerably. A total of 664 doses of oral analgesics, mainly paracetamol, was given to the hysterectomy group whereas only 342 doses were given to the cholecystectomy group. One reason for this could be that 46 of the 51 women who had a hysterectomy complained of "wind pain," and 25 of these considered this to be worse than the pain from the wound. Wind pain often lasted for several days after surgery and was usually treated with paracetamol and peppermint water.

There is a depressing similarity between our results and those previously published. ${ }^{1.3}$ For $40 \%$ of our patients the postoperative period had been very painful. The average pain intensity experienced during the first 24 hours was perceived as $60 \%$ of the maximum. Although the intensity lessened day by day, patients were recording quite high pain scores as late as the sixth postoperative day. A three hour delay between the return of pain and administration of the next analgesic dose was commonplace, and one patient had to wait 17 hours.

Why is the standard of postoperative pain relief still so unsatisfactory despite well publicised studies during the past 15 years? We think that there are three reasons. Firstly, a lower level of pain relief is expected by the patient; for $69 \%$ the pain experienced was at least as severe as they had expected. Secondly, staff tend to underestimate the amount of analgesia required to maintain pain relief; although the initial dose prescibed may not have been too low, no attempt was made to assess the effect of this so that it could be adjusted to provide optimum pain relief and then repeated at convenient intervals. Thirdly, there is a continuing fear, expressed by a fifth of the nurses questioned, of opioid dependence; half of these nurses admitted that this fear would influence their selection of the dose and dose interval whenever choice was permitted. Patients expect ineffective pain relief and their carers ensure that they are not disappointed.

What can be done to improve postoperative pain relief? The level of pain that patients expect is determined by any previous operative experience (if they remember it) and information given to them preoperatively. Interestingly, when asked to name one or more people who inform patients before surgery 
about possible postoperative pain doctors believed that this was most often done by anaesthetists and other doctors, and nurses believed that they themselves were the main informants, but the patients said that they had been informed most commonly by their family and friends. An information sheet about postoperative pain was thought useful by $89 \%$ of patients, $75 \%$ of nurses, and $42 \%$ of doctors. Other patients felt that such information coul increase anxiety by causing them to dwell too much on the painful aspects of the operation. Egbert et al reduced analgesic requirements by half when anaesthetists spent time before the operation explaining about pain and how to reduce its severity by protecting and relaxing abdominal musculature. Other studies have also shown that oral and written information, if presented sensitively, can reduce postoperative pain and anxiety. ${ }^{67}$

The extent to which a patient's response to the first dose(s) of analgesia is assessed depends on staff being aware that requirements vary (most of the staff we questioned seemed to know this) and having the time and the inclination to carry out such an assessment. Judging by the number of visual analogue scales left uncompleted in our study, the time was often not available on account of other nursing duties. Perhaps staff:patient ratios on surgical wards should be increased to take account of this. Another possible solution is demand analgesia with syringe pumps,${ }^{8}$ but these are expensive to install and require experienced staff to educate and supervise patients in their use.

It is well known that medical and nursing staff overestimate the risk of addiction from opioid analgesia, ${ }^{149}$ and one fifth of all nurses we questioned were concerned about this. The real risk has been estimated at $1: 3000$ patients. ${ }^{10}$

The results of this study highlight deficiencies that prevent optimal postoperative pain relief. Not only are patients' expectations of pain relief low but for many the reality is even worse. These expectations need to be raised by better communication: information given to patients preoperatively not only helps but would be well received. The level of pain relief that medical and nursing staff aim to provide must also rise. Education for nursing staff in optimal administration of analgesia must reach both trainees and qualified staff to achieve and maintain a high standard.

We thank the patients and the nursing and medical staff on the surgical wards at City General Hospital for their cooperation.

1 Cohen FL. Post surgical pain relief: patients' status and nurses' medication choice. Pain 1980:9:265-74.

Cronin M, Redfern PA, Utting JE. Psychometry and postoperative complaints in surgical patients. Br $\mathcal{A}$ Anaesth 1973;45:879.

3 Cartwright PD. Pain control after surgery: a survey of current practice. Ann R Coll Surg Engl 1985;67:13-6.

4 Huskisson EC. Measurement of pain.Lancet 1974;ii:1127-31.

5 Egbert LD, Battit GE, Welch CE, et al. Reduction of postoperative pain by encouragement and instruction of patients. N Engl F Med 1964;270:825-6.

6 Leigh JM, Walker J, Janaganathan P. Effect of preoperative anaesthetic visi on anxiety. Br Med J 1977;ii:987-9.

7 Hayward J. Information-a prescription against pain. London: Royal College of Nursing, 1975. (Research project 120 .)

8 Keeri-Szanto M, Heaman S. Postoperative demand analgesia. Surg (jynecol Obstet 1972;134:647-51.

9 Marks RM, Sachar EJ. Under treatment of medical in-patients with narcotic analgesia. Ann Intern Med 1973;78:173-81.

10 Porter J, Jick H. Addiction rate in patients treated with narcotics. N Engl F Med 1980;302:123.

(Accepted 17 April 1990)

\begin{abstract}
Department of Obstetrics and Gynaecology, University of Birmingham, and Dudley Road Hospital, Birmingham

D M Luesley, MD, senior

lecturer

J Cullimore, MRCOG, research fellow

C W E Redman, MD, lecturer F G Lawton, MD, lecturer D R Williams, FIMLs, chief medical laboratory scientific officer

E J Buxton, MRCOG, research fellow

\section{Birmingham and Midland Hospital for Women, Birmingham B11 4HI T P Rollason, FRCPATH, senior lecturer \\ J M Emens, MD, consultant gynaecologist}

Correspondence to: Dr D M Luesley, Academic Department of Obstetrics and Gynaecology, Dudley Road Hospital, Birmingham B18 7QH.
\end{abstract}

\title{
Loop diathermy excision of the cervical transformation zone in patients with abnormal cervical smears
}

\author{
D M Luesley, J Cullimore, C W E Redman, F G Lawton, J M Emens, T P Rollason, D R Williams, \\ E J Buxton
}

Abstract
Objective-To determine the efficacy and morbidity of fine loop diathermy excision of the cervical transformation zone as applied to the management of outpatients with abnormal cervical smears.

Design-Prospective programme trial with six month follow up.

Setting - Two hospital based colposcopy clinics.

Patients-616 Patients aged 16-60 with abnormal cervical smears.

Interventions-After colposcopic and cytological assessment excision of the cervical transformation zone by fine loop diathermy under local anaesthesia in the outpatient department.

Main outcome measures-Time to complete the treatment, immediate morbidity in terms of discomfort and bleeding, and cytological and colposcopic findings at six months.

Results - Treatment was completed in a mean of 3.47 minutes (SD 1.99). Immediate morbidity was minimal, and histological specimens were adequate in over $90 \%$ of cases. Almost two thirds of patients were treated at their first visit to the clinic. 58 Patients $(9.4 \%)$ failed to attend for follow up at six months and one had had a hysterectomy. Of the 557 patients who attended for colposcopic and cytological follow up at six months, $506(91 \%)$ were normal cytologically and $19(3.4 \%)$ had histologically confirmed persistence of cervical intraepithelial neoplasia. The overall confirmed failure rate of the technique was $4 \cdot 4 \%$.

Conclusion-Loop diathermy excision is an effective treatment with low morbidity and is an appropriate modality for patients with abnormal cervical smears.

\section{Introduction}

The concept of excising the abnormal transformation zone of the cervix should cytological or colposcopic criteria suggest the presence of intraepithelial neoplasia is not new. Cold knife and diathermy conisation and more recently carbon dioxide laser conisation are proved effective techniques, although they require either general anaesthesia or expensive equipment. Morbidity is well documented. Outpatient excision of the transformation zone using the carbon dioxide laser has also been shown to be feasible but also requires equipment, skill, and time that are not always available.

Diathermy generators are cheap, easy to maintain, and available in nearly every hospital. With minimal adaption they can be used in an outpatient setting either to totally excise ${ }^{1}$ or take a biopsy sample of the cervical transformation zone. ${ }^{2}$ Furthermore, being an excisional method of management, treatment can be undertaken at first contact, so dispensing with the necessity for a pretreatment assessment.

There have been no large series prospectively docu- 